\title{
Frequent E-cadherin Gene Inactivation by Loss of Heterozygosity in Pleomorphic Lobular Carcinoma of the Breast
}

José Palacios, M.D., David Sarrió, B.S., María C. García-Macias, M.D., Bonita Bryant, M.T., Mark E. Sobel, M.D., María J. Merino, M.D.

Laboratory of Breast and Gynecological Cancer (JP, DS), Molecular Pathology Program, Centro Nacional de Investigaciones Oncológicas, Madrid, Spain; Service of Pathology (MCG), Hospital Clinico Universitario, Salamanca, Spain; and Department of Pathology, National Cancer Institute, National Institutes of Health, Bethesda, Maryland (BB, MES, MJM)

Pleomorphic lobular carcinoma of the breast is a variant of infiltrating lobular carcinoma that has poor prognosis. The pleomorphic appearance of this variant hinders its correct identification and differentiation from ductal carcinoma. The analysis of E-cadherin glycoprotein expression is a powerful tool for distinguishing lobular from ductal carcinomas, because complete loss of E-cadherin expression occurs in most infiltrating lobular tumors and lobular carcinomas in situ, but not in ductal tumors. In the present study, we have evaluated E-cadherin expression by immunohistochemistry in a series of 29 pleomorphic lobular breast carcinomas, including 7 cases with an in situ component. Complete loss of E-cadherin expression was observed in all the cases $(29 / 29,100 \%)$, in invasive and in situ components. To understand better the mechanisms underlying E-cadherin inactivation in this tumor type, the frequency of loss of heterozygosity at the E-cadherin gene locus $(16 q 22.1)$ was analyzed. All informative tumors $(27 / 27,100 \%)$ showed loss of heterozygosity, thus implying a strong association between loss of E-cadherin expression and loss of heterozygosity at 16q22.1. Moreover, loss of heterozygosity was detected in all in situ components analyzed. These results imply that in terms of E-cadherin inactivation, pleomorphic lobular tumors are identical to classic infiltrating lobular carcinomas and distinct from ductal tu-

Copyright ( $(2003$ by The United States and Canadian Academy of Pathology, Inc.

VOL. 16, NO. 7, P. 674, 2003 Printed in the U.S.A.

Date of acceptance: March 28, 2003.

Supported in part by a research grant from the Fondo de Investigación Sanitaria (BEFI, 01/9132, to DS).

Address reprint requests to: José Palacios, M.D., Programa de Patología Molecular, Centro Nacional de Investigaciones Oncológicas (CNIO), c./

Melchor Fernández Almagro n 3, 28029 Madrid, Spain; fax: 34-91-22469-23; e-mail: jpalacios@cnio.es.

DOI: 10.1097/01.MP.0000073974.42583.F7 mors, and therefore they should be considered a variant of lobular carcinoma of the breast, despite their aggressive behavior.

KEY WORDS: E-cadherin, Loss of heterozygosity, Microdissection, Pleomorphic lobular breast carcinoma.

Mod Pathol 2003;16(7):674-678

Pleomorphic lobular carcinoma of the breast is a variant of infiltrating lobular carcinoma that has poor prognosis (1). Although it shares many of the histological features of infiltrating lobular carcinoma, the pleomorphic appearance of this variant contrasts with the cytological uniformity of classic infiltrating lobular carcinoma, thus hindering its correct identification and differentiation from ductal carcinoma (2). Identical histological features to those of infiltrating pleomorphic lobular carcinoma have recently been described in an entity termed pleomorphic lobular carcinoma in situ, which may sometimes be misinterpreted as ductal carcinoma in situ (3). Therefore, it seems that pleomorphic lobular carcinoma shares some characteristics with classic infiltrating lobular cancer, although it may also have distinctive features, thus raising the question of whether pleomorphic lobular carcinoma is a tumor of lobular nature. In this context, several studies have demonstrated that the analysis of E-cadherin expression is a powerful tool for distinguishing lobular from ductal carcinomas, even in those infiltrating and in situ tumors with indeterminate features $(4-8)$.

E-cadherin is a transmembrane glycoprotein that mediates cell-cell adhesion in epithelial tissues (9). Dysfunction of the E-cadherin/catenin adhesion complex is involved in many human cancers (10, 11). Complete loss of E-cadherin expression occurs in most invasive lobular carcinomas and lobular 
carcinomas in situ, but not in invasive ductal cancer or ductal carcinoma in situ $(4,5,12)$. Moreover, abnormal cytoplasmic expression of E-cadherin only occurs in lobular neoplasms (in a subset of tumors), whereas in about $50 \%$ of ductal tumors, reduced levels of membrane-bound E-cadherin have been reported $(8,13)$. Consistent with these findings, E-cadherin gene $(\mathrm{CDH})$ has been reported to be frequently mutated in infiltrating lobular carcinoma (14-16) and lobular carcinoma in situ (17), but not in ductal tumors (18). In most lobular tumors, the remaining wild-type $C D H 1$ allele is inactivated by loss of heterozygosity (LOH) at the $C D H 1$ locus (16q22.1) $(16,18)$. Genetic losses affecting the $16 \mathrm{q}$ region are frequently found in lobular tumors $(80-100 \%)(16,17,19)$. Therefore, because complete loss of E-cadherin expression and high frequency of LOH at 16q22.1 are characteristic of lobular tumors (20), we have investigated whether these alterations occur in a series of 29 pleomorphic lobular breast carcinomas to confirm the lobular nature of this entity.

\section{MATERIALS AND METHODS}

\section{Tumor Samples}

This study is of a series of 29 formalin-fixed, paraffin-embedded pleomorphic lobular carcinomas that were selected according to morphological criteria $(1,21)$. Briefly, individual tumor cells were large and globoid, with abundant eosinophilic granular cytoplasm and irregular hyperchromatic nuclei. The tumor cells infiltrated in the classical single file and targetoid pattern of growth. Additionally, seven cases had an associated in situ component. The clinicopathological features were described in a previous study (22). Briefly, the median patient's age was 63 years, and $71 \%$ were postmenopausal. Tumor size ranged from 1.2 to $2.5 \mathrm{~cm}$. Sixteen percent of the tumors were Stage I, 50\% were Stage II, $31 \%$ were Stage III, and $3 \%$ were Stage IV. Eighty-one percent of the tumors were positive for estrogen receptors, and $67 \%$, for progesterone receptors.

\section{Immunohistochemistry}

Two-micrometer-thick tissue sections were cut onto sialinated slides, deparaffinized, and cleared and stripped of endogenous peroxidase. For heatinduced antigen retrieval, sections were immersed in boiling $10 \mathrm{~mm}$ sodium citrate at $\mathrm{pH} 6.5$ for 2 minutes in a pressure cooker. Sections were then incubated with a primary monoclonal antibody against E-cadherin (HECD-1; Zymed, San Francisco, CA; 1:200 dilution). The slides were developed with diaminobenzidine, counterstained with hematoxylin, and subjected to qualitative and quantitative visual assessment. Normal breast tissues known to express E-cadherin, were included in each staining run as positive controls. Additionally, most studied tumor sections also included normal breast epithelium as an internal positive control. In negative controls, the primary antibodies were omitted. Composite immunoreactivity scores were obtained by adding the values of the immunoreaction intensity and the relative abundance of immunoreactive cells, as previously reported (4).

\section{Microdissection and DNA Extraction}

To avoid contamination of tumoral samples by normal cells, tumoral cells were manually microdissected from the invasive component in all tumors and from the in situ component of eight cases. Separate cell populations of normal ductal epithelium and stroma were also microdissected. DNA was extracted from 5 - $\mu$ m-thick sections under direct light microscopic visualization with a disposable 30-gauge needle using the previously described microdissection technique (23). Digestion of the microdissected cells was carried out following the proteinase-K-based method, as previously described (22). We consecutively analyzed microdissected tumor cells. Samples were discarded and not subjected to analysis when we were concerned about the quality of the DNA and its ability to be amplified.

\section{Assessment of $\mathrm{LOH}$ at $\mathrm{CDH} 1$ locus}

Loss of heterozygosity at the $\mathrm{CDH} 1$ locus (16q22.1) was assessed using two highly polymorphic microsatellite markers (D16S265 and D16S752) that map close to $\mathrm{CDH} 1$ gene (from the Genome Database, www.gdb.org). To ensure the reliability of the results, each marker was PCR amplified twice in both the normal and tumoral DNA. Fluorescentlabeled PCR products were diluted and analyzed in an automated sequencing system (ABI Prism 3700; Applied Biosystems, PE) using Genescan software (Applied Biosystems, Warrington, UK). LOH was calculated according to a previously described formula (24).

\section{RESULTS}

Pleomorphic Lobular Carcinoma Show Complete Absence of E-Cadherin Expression

In contrast to normal ducts, where there was always strong membranous staining, all pleomorphic lobular tumors $(29 / 29,100 \%)$ showed complete loss of E-cadherin immunostaining (Fig. 1C). This complete absence of E-cadherin was also found in the in situ component of the tumors, im- 
plying that E-cadherin inactivation is an early event in the tumorigenesis of lobular carcinomas (Fig. 1D).

\section{E-Cadherin Gene Is Inactivated by Loss of Heterozygosity in Pleomorphic Lobular Carcinomas}

All pleomorphic lobular carcinomas studied were informative for at least one of the microsatellite markers used. Nineteen of 29 (65\%) cases were informative for the microsatellite marker D16S752, of which 19/19 showed LOH. Using the D16S265 marker, 22/29 (76\%) pleomorphic lobular carcinomas were informative, and all of these showed $\mathrm{LOH}$.

The same results were obtained in the duplicate assays on all the cases analyzed.

In summary, $\mathrm{LOH}$ affecting $\mathrm{CDH} 1$ locus was detected in 27/27 (100\%) informative tumors (Fig. 1E).
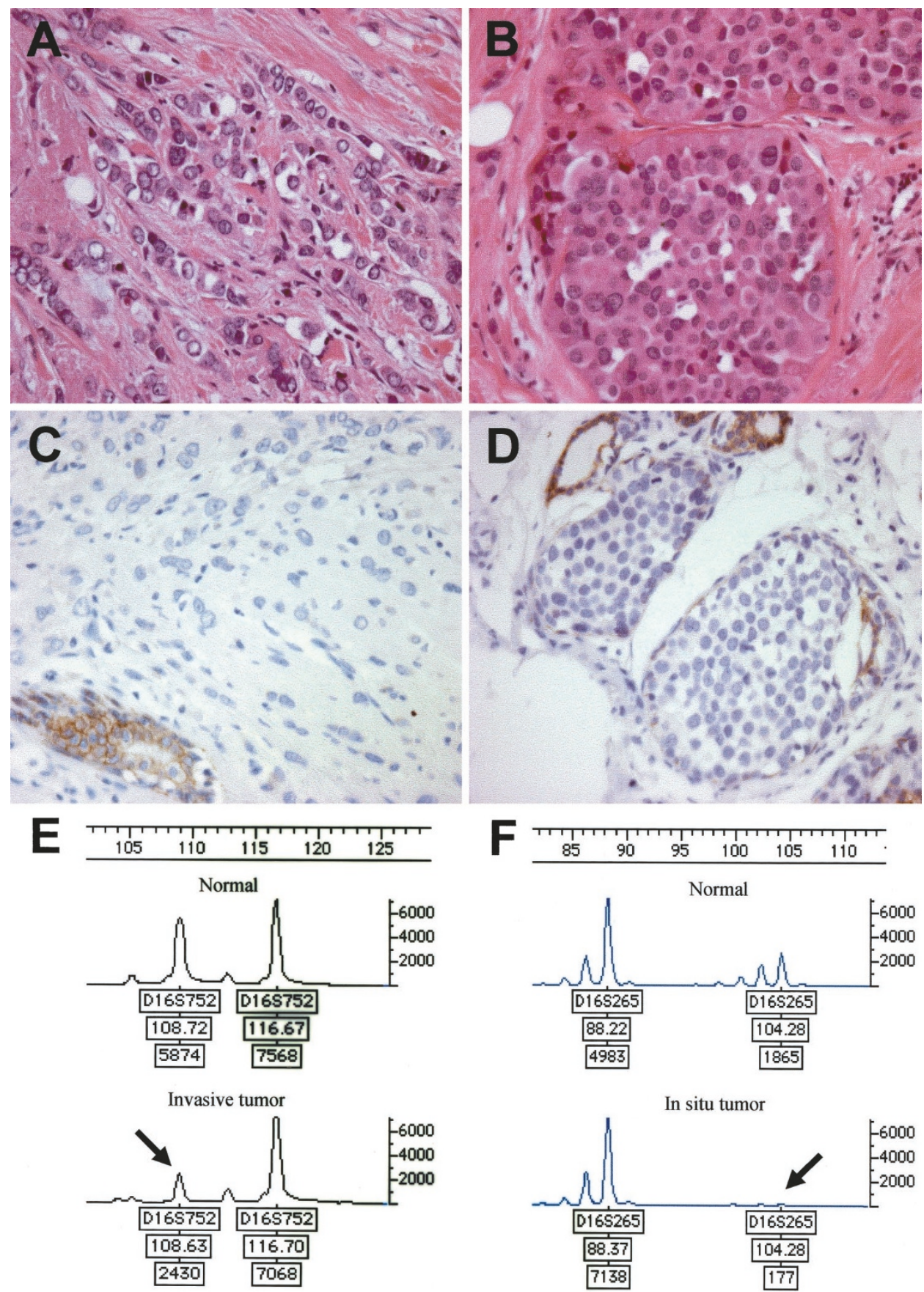

FIGURE 1. Hematoxylin-eosin staining of an invasive pleomorphic lobular carcinoma (A) and the corresponding in situ component (B). E-cadherin expression is completely lost in pleomorphic lobular tumors (C) and its associated carcinoma in situ (D) but is retained in the membrane of epithelial cells in normal ducts. LOH at CDH1 locus is frequently detected in both invasive (E) and in situ (F) pleomorphic lobular tumors. Note that one allele is lost in the tumor (marked by arrows), in contrast to its paired normal tissue. 
Additionally, LOH in E-cadherin gene was also detected in all in situ components analyzed (Fig. 1F).

\section{DISCUSSION}

Pleomorphic lobular carcinoma is a distinctive subtype of invasive breast cancer and accounts for approximately $1 \%$ of all epithelial malignancies of the breast.

It is of growing interest to establish the distinctive clinicopathological features and the molecular characteristics of pleomorphic lobular carcinoma to identify this aggressive tumor clearly. Efforts have been made recently to differentiate pleomorphic lobular carcinoma from classic infiltrating lobular and ductal tumors using immunohistochemistry. For instance, all pleomorphic lobular carcinomas tumors are positive for the apocrine marker gross cystic disease fluid protein-15 (GCDFP-15), confirming that in contrast to classic infiltrating lobular cancer, pleomorphic lobular carcinoma shows apocrine differentiation $(21,25,26)$. Pleomorphic lobular cancer and classic infiltrating lobular tumors share elevated levels of cytokeratin and epithelial membrane antigen, but pleomorphic lobular cancer has a higher level of chromogranin expression (26). Moreover, pleomorphic lobular carcinoma frequently tends to maintain estrogen and progesterone immunoreactivity $(22,27)$, although a low level of hormone receptor expression has also been reported $(25,26)$. With regard to proliferation and apoptosis, pleomorphic lobular cancer has been shown to overexpress Her2 and to have p53 nuclear expression in $48-80 \%$ of cases. Moreover, pleomorphic lobular cancers are generally positive for bcl-2 and have a low apoptotic index. Thus, the frequent expression of the unfavorable markers Her-2 and p53 and the generally low level of apoptosis may contribute to the aggressive behavior of pleomorphic lobular carcinoma (22, 26, 27). Unfortunately, very little is known about the cytogenetic alterations that characterize pleomorphic lobular tumors. Using flow cytometry, a higher frequency of aneuploid tumor cells in pleomorphic lobular carcinomas than in classic infiltrating lobular carcinomas was found (28). More recently, loss of heterozygosity affecting p53, Her 2, BRCA1, and ESR loci has been reported in pleomorphic lobular tumors (22).

In the current study, we have evaluated whether pleomorphic lobular carcinomas show the same alterations in E-cadherin gene and protein expression as those described in infiltrating lobular tumors. Using immunohistochemistry, we have observed that all pleomorphic lobular tumors showed complete loss of E-cadherin expression, an alteration that is characteristic of lobular tumors. These results support previous observations in infiltrating lobular carcinomas indicating that most lobular tumors, independent of their histological subtype, show complete E-cadherin inactivation $(8,29,30)$. Various mechanisms are involved in the inactivation of E-cadherin in breast carcinomas. Truncating mutations in the $\mathrm{CDH1}$ gene are frequent in infiltrating lobular cancers, whereas they are rarely found in ductal tumors $(14,18)$. Transcriptional silencing by promoter hypermethylation has also been described in ductal (31) and lobular tumors (15). However, the most frequent alteration affecting $\mathrm{CDH} 1$ gene in breast tumors is the loss of heterozygosity at $16 \mathrm{q}$, which occurs in about $50 \%$ of ductal $(19,32)$ and $80 \%$ of lobular carcinomas $(16$, 18). Nonetheless, in contrast to lobular tumors, $\mathrm{LOH}$ at $16 \mathrm{q}$ is not associated with decreased levels of E-cadherin in invasive ductal cancer, suggesting the presence of another putative tumor suppressor gene in $16 q$ that could play an important role in ductal tumorigenesis (19).

In our series of pleomorphic lobular carcinomas, we found that all E-cadherin-negative tumors showed $\mathrm{LOH}$ at $\mathrm{CDH} 1$ locus, thus implying a strong association between loss of E-cadherin expression and $\mathrm{LOH}$ at $16 \mathrm{q} 21-22$. Additionally, mutations and hypermethylation affecting $C D H 1$ have been detected by us in a number of pleomorphic lobular tumors (unpublished observations), supporting the hypothesis that the same mechanisms of E-cadherin inactivation are present in pleomorphic lobular carcinomas and classic lobular cancers. In fact, we have investigated E-cadherin immunoreactivity in the in situ component of seven cases of pleomorphic lobular carcinoma and found that all of them featured complete loss of E-cadherin expression. This finding confirms that unlike the case with ductal carcinoma in situ, almost all cases of lobular carcinoma in situ lack E-cadherin expression $(4,5,8,12,13)$. Consistent with this, it has been demonstrated in a small number of samples that E-cadherin mutations and $\mathrm{LOH}$ at 16q21-22 appear in the in situ component adjacent to invasive lobular carcinomas but also in lobular carcinoma in situ without invasive carcinoma (17), thus implying that E-cadherin loss is an early event in lobular tumorigenesis. Here, we report that $\mathrm{LOH}$ at $\mathrm{CDH} 1$ locus is also a common alteration in the in situ component of pleomorphic lobular carcinoma, because it was detected in all cases analyzed. Because LOH data from lobular carcinoma in situ are currently very limited, our results suggest that $\mathrm{LOH}$ at 16q21-22 is a frequent alteration in lobular carcinoma in situ. Moreover, recent cytogenetic studies using the comparative genomic hybridization (CGH) technique have revealed that loss of material from $16 \mathrm{q}$ and $17 \mathrm{p}$ are the most frequent alterations in lobular carcinoma in situ $(33,34)$. 
In summary, our data demonstrate that in terms of E-cadherin inactivation, pleomorphic lobular tumors are identical to classic infiltrating lobular carcinomas and distinct from ductal tumors. Thus, pleomorphic lobular carcinoma should be considered as a variant of lobular carcinoma of the breast, despite its aggressive behavior.

\section{REFERENCES}

1. Weidner N, Semple JP. Pleomorphic variant of invasive lobular carcinoma of the breast. Hum Pathol 1992;23:1167-71.

2. Page DL, Anderson TJ, Rogers LW. Diagnostic histopathology of the breast. 2nd ed. Edinburgh, Scotland: Churchill Livingstone; 1988.

3. Frost AR, Tsangaris TN, Silverberg SG. Pleomorphic lobular carcinoma in situ. Case Rev 1996;1:27-31.

4. Gamallo C, Palacios J, Suarez A, Pizarro A, Navarro P, Quintanilla M, et al. Correlation of E-cadherin expression with differentiation grade and histological type in breast carcinoma. Am J Pathol 1993;142:983-7.

5. Moll R, Mitze M, Frixen UH, Birchmaier W. Differential loss of E-cadherin expression in infiltrating ductal and lobular carcinomas. Am J Pathol 1993;143:1731-42.

6. Maluf HM, Swanson PE, Koerner FC. Solid low-grade in situ carcinoma of the breast: role of associated lesions and E-cadherin in differential diagnosis. Am J Surg Pathol 2001; 25:237-44.

7. Jacobs TW, Pliss N, Kouria G, Schnitt SJ. Carcinomas in situ of the breast with indeterminate features: role of E-cadherin staining in categorization. Am J Surg Pathol 2001;25:229-36.

8. Acs G, Lawton TJ, Rebbeck TR, LiVolsi VA, Zhang PJ. Differential expression of E-cadherin in lobular and ductal neoplasms of the breast and its biologic and diagnostic implications. Am J Clin Pathol 2001;115:85-98.

9. Takeichi M. Cadherin cell adhesion receptors as a morphogenetic regulator. Science 1991;251:1451-5.

10. van Aken E, de Wever O, Correira da Rocha AS, Mareel M. Defective E-cadherin/catenin complexes in human cancer. Virchows Arch 2001;439:725-51.

11. Wijnhoven BPL, Dinjens WNM, Pignatelli M. E-cadherincatenin cell-cell adhesion complex and human cancer. Br J Surg 2000;87:992-1005.

12. Palacios J, Benito N, Pizarro A, Suarez A, Espada J, Cano A, et al. Anomalous expression of P-cadherin in breast carcinoma. Correlation with E-cadherin expression and pathological features. Am J Pathol 1995;146:605-12.

13. de Leeuw WJF, Berx G, Vos CBJ, Peterse JL, van de Vijver MJ, Litvinov S, et al. Simultaneous loss of E-cadherin and catenins in invasive lobular breast cancer and lobular carcinoma in situ. J Pathol 1997;183:404-11.

14. Berx G, Cleton-Jansen A-M, Nollet F, de Leeuw WJF, van de Vijver MJ, Cornelisse CJ, et al. E-cadherin is a tumor/invasion tumor suppressor gene in human lobular breast cancer. EMBO J 1995;14:6107-15.

15. Droufakou S, Deshmane V, Roylance R, Hanby A, Tomlinson I, Hart IR. Multiple ways of silencing E-cadherin gene expression in lobular carcinoma of the breast. Int J Cancer 2001;92:404-8.

16. Huiping C, Sigurgeirsdottir JR, Jonasson JG, Eiriksdottir G, Johannsdottir JT, Egilsson V, et al. Chromosome alterations and E-cadherin gene mutations in human lobular breast cancer. Br J Cancer 1999;81:1103-10.

17. Vos CBJ, Clenton-Jansen AM, Berx G, de Leeuw WJF, ter Haar NT, van Roy F, et al. E-cadherin inactivation in lobular carcinoma in situ of the breast: an early event in tumorigenesis. Br J Cancer 1997;76:1131-3.
18. Berx G, Cleton-Jansen A-M, Strumane K, de Leeuw WJF, Nollet F, van Roy F, et al. E-cadherin gene is inactivated in a majority of invasive human lobular breast cancer by truncation mutations throughout its extracellular domain. Oncogene 1996;13:1919-25.

19. Cleton-Jansen AM, Callen DF, Seshadri R, Goldup S, Mccallum B, Crawford J, et al. Loss of heterozygosity mapping at chromosome arm 16q in 712 breast tumors reveals factors that influence delineation of candidate regions. Cancer Res 2001;61:1171-7.

20. Berx G, Van Roy F. The E-cadherin/catenin complex: an important gatekeeper in breast cancer tumorigenesis and malignant progression. Breast Cancer Res 2001;3:289-93.

21. Eusebi V, Magalhaes F, Azzopardi JG. Pleomorphic lobular carcinoma of the breast. An aggressive tumor showing apocrine differentiation. Hum Pathol 1992;23:655-62.

22. Middleton LP, Palacios DM, Bryant BR, Krebs P, Otis CN, Merino MJ. Pleomorphic lobular carcinoma: morphology, immunohistochemistry, and molecular analysis. Am J Surg Pathol 2000;24:1650-6.

23. Zhuang Z, Bertheau P, Emmert-Buck MR, Liotta LA, Gnarra J, Linehan WM, et al. A microdissection technique for archival DNA analysis of specific cell populations in lesions less than $1 \mathrm{~mm}$ in size. Am J Pathol 1995;146(3):620-5.

24. Canzian F, Salovaara R, Hemminki A, Kristo P, Chadwick RB, Aaltonen LA, et al. Semiautomated assessment of loss of heterozygosity and replication error in tumors. Cancer Res 1996;56(14):3331-7.

25. Bentz JS, Yass N, Clayton F. Pleomorphic lobular carcinoma of the breast: clinicopathologic features of 12 cases. Mod Pathol 1998;11:814-22.

26. Radhi JM. Immunohistochemical analysis of pleomorphic lobular carcinoma: higher expression of p53 and chromogranin and low expression of ER and PgR. Histopathology 2000;36:156-60.

27. Frolik D, Caduff R, Varga Z. Pleomorphic lobular carcinoma of the breast: its cell kinetics, expression of oncogenes and tumour suppressor genes compared with invasive ductal carcinomas and classical infiltrating lobular carcinomas. Histopathology 2001;39(5):503-13.

28. Weidner N, Bennington J. Correlation of DNA ploidy, DNA S-phase and nuclear diameter with classical and pleomorphic variant of invasive lobular carcinoma. Lab Invest 1994; 70:24A.

29. Wahed A, Connelly J, Reese T. E-cadherin expression in pleomorphic lobular carcinoma: an aid to differentiation from ductal carcinoma. Ann Diagn Pathol 2002;6:349-51.

30. Sneige N, Wang J, Baker BA, Krishnamurthy S, Middleton LP. Clinical, histopathologic, and biologic features of pleomorphic lobular (ductal-lobular) carcinoma in situ of the breast: a report of 24 cases. Mod Pathol 2002;15:1044-50.

31. Graff JR, Herman JG, Myöhänen S, Baylin SB, Vertino PM. Mapping patterns of $\mathrm{CpG}$ island methylation in normal and neoplastic cells implicates both upstream and downstream regions in de novo methylation. J Biol Chem 1997;272(35): 22322-9.

32. Shen CY, Yu JC, Lo YL, Kuo CH, Yue CT, Jou YS, et al. Genome-wide search for loss of heterozygosity using laser capture microdissected tissue of breast carcinoma: an implication for mutator phenotype and breast cancer pathogenesis. Cancer Res 2000;60:3884-92.

33. Etzell JE, Devries S, Chew K, Florendo C, Molinaro A, Ljung $\mathrm{BM}$, et al. Loss of chromosome $16 \mathrm{q}$ in lobular carcinoma in situ. Hum Pathol 2001;32:292-6.

34. Lu YJ, Osin P, Lakhani SR, Di Palma S, Gusterson BA, Shipley JM. Comparative genomic hybridization analysis of lobular carcinoma in situ and atypical lobular hyperplasia and potential roles for gains and losses of genetic material in breast neoplasia. Cancer Res 1998;58:4721-7. 